\title{
Effect of Oral Environment on New Fiber-Reinforced Composite System
}

W SISWOMIHARDJO ${ }^{* 1-3}, S^{2}$ SUNARINTYAS ${ }^{1-3}$, MK HERLIANSYAH ${ }^{2-3}, \quad J P$ MATINLINNA ${ }^{4}\left({ }^{1}\right.$ Faculty of Dentistry, Universitas Gadjah Mada, Indonesia, ${ }^{2}$ Faculty of Engineering, Universitas Gadjah Mada, Indonesia, ${ }^{3}$ School of Graduate Studies, Universitas Gadjah Mada, Indonesia, ${ }^{4}$ Faculty of Dentistry, University of Hong Kong).

\section{Abstract}

Purpose: Fiber-reinforced composite (FRC) is consists of matrix that is reinforced with thin fibers, which have high tensile strength and flexural modulus (Zhang and Matinlinna. Silicon 2012 4: 73). The bis-GMA-MMA combination as the resin matrix is widely used as resin matrix, whereas bis-GMA is reported as the most cytotoxic monomer among dental resin composite monomers (Moharamzadeh et al. Material 2009 2:514). Resin matrix 1,6 hexanediol dimethacrylate (HDMA) has similar reactive groups than bis-GMA, and is not listed as carcinogens (Vallittu and Sevelius. J Prosthet Dent 2000 84: 413). The purpose of this study was to investigate the water sorption of a new resin matrix system of FRC based on HDMA.

Materials and Methods : Materials used were: E-glass fibre bundles (Stick Tech, Finland), HDMA (Esstech, USA), bis-GMA (Sigma-Aldrich, USA), MMA (ProSciTech, Australia), CQ (Esstech, USA) and CEMA (Esstech, USA).: Fifteen specimens (2mm $\times 2 \mathrm{~mm} \times 25 \mathrm{~mm}$ ) were prepared and divided into 3 groups. Composition of group-1: 78.4\%HDMA+19.6\%MMA+1.0\%CQ+1.0\%CEMA;group-2:49.0\%HDMA +49.0\%MMA $+1.0 \% \mathrm{CQ}+1.0 \% \mathrm{CEMA}$; and group-3 $: 78.4 \%$ bis-GMA + $19.6 \% \mathrm{MMA}+1.0 \% \mathrm{CQ}+$ $1.0 \%$ CEMA. Specimens with two fiber rovings of $25 \mathrm{~mm}$ long were placed in a mould, and monomers were added and light-cured with halogen light-curing unit on both sides for $3 \times 40$ s. Specimens were immersed in $15 \mathrm{ml}$ distilled water of $37^{\circ} \mathrm{C}$ for 21 days. The difference in weights, before and after immersion were recorded. Data obtained were analyzed by one-way ANOVA and LSD.

Results: As for the difference in weights (before and after immersion), group-1 showed the lowest average $(0.004 \% 0$, followed by group-3 $(0.003 \%)$ and group-2 $(0.01 \%)$. Statistical analysis (ANOVA) proved a significant difference among the three groups $(p<0.05)$. Result of LSD showed there was a significant difference between group-1 and group-2 $(p<0.05)$ but no significant difference between group-1 and group-3 $(p>0.05)$.

Conclusions: It can be concluded that FRC based on HDMA matrix system (group1 ) is comparable to bis-GMA (group-3) on its water sorption.

\section{Introduction}

The loss of tooth that might cause functional disabilities, need the construction of prosthesis. One of the prosthesis which is commonly used is the crown and bridge, more specifically is the porcelain-fused-to-metal. The advantage of this prosthesis is the natural appearence and good mechanical properties. Unfortunately, since there is porcelain in the construction it is relatively brittle, easily to crack or to fracture (Hobkirk et al., 2003). Another disadvantage that might be happened, is corotion in the metal part (Freilich et al., 2000). 
The development of fiber reinforced composite (FRC) has provided the dentists the possibility of fabricating resin-bonded with esthetically good and metal-free tooth restorations for single and multiple teeth replacement (Garoushi et al., 2011). And nowadays FRC is gaining its popularity (Schutt et al., 2004). Fiber reinforced composite is a modification of dental resin composite using either glass or carbon fibers (Mc Cabe and Walls, 2007). This material has fine thin fibers as reinforcement which gives good tensile strength and flexural modulus (Mallick, 2007). The superiority of FRC compared to resin composite is its strength (Van Noort, 2007). Basically FRC has at least two distinct constituents, the reinforcing component which gives good strength and stiffness, while the surrounding matrix supports reinforcement (Freilich et al., 2000). It is stated that glass fibers have high tensile strength, good impact and compression properties which make it more desired reinforcing material (Le Bell-Ronnlof, 2012).

The structure of FRC is an interpenetrating polymer network (IPN) structure, whereas the matrix is consisted from a crosslinking polymer, a linear polymer and a photoinitiator to react the polymerization (Zhang and Matinlinna, 2011). The mechanical strength of FRC depends on the impregnition of fibers within the resin matrix and adhesion of fibers to the matrix (Valittu, 1998; Valittu, 1999; Valittu, 2002). One of the most commonly used resin matrix which forms highly crosslinking polymer structures is bis-phenol-A-diglycidylmethacrylate (bis-GMA) (Zhang and Matinlinna, 2011). Methyl methacrylate (MMA) a linear polymer (Zhang and Matinlinna, 2011) is joined to form a crosslinking polymer (Anusavice, 2009). The photoinitiator includes a photosensitizer and a reducing agent. Camphoroquinon (CQ) and N-N-cyanoethyl methylaniline (CEMA) are the common used photosensitizer and reducing agents (Zhang and Matinlinna, 2011). Some released compounds might cause biological reactions (Soderholm and Marioti, 1999), and a case of allergic contact caused by bis-GMA was reported (Stoeva et al., 2008). BisGMA is also reported as the most cytotoxic monomer among dental resin composite monomers (Moharamzadeh et al., 2009). Since the use of bis-GMA is considered to be relatively hazardous, nowadays the use of other matrixes are gaining more and more interest. Next to this, there is a growing need to replace bis-GMA which is relatively hydrophilic by other hydrophobic matrixes which exhibit lower water uptake (Sederidou et al., 2004). The structure of bis-GMA is as figured below

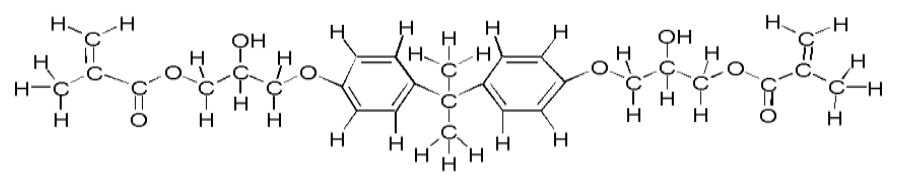

Figure 1. The structure of bis-phenol-A-glycidylmethacrylate (bis-GMA)

Resin matrix 1,6 hexanediol dimethacrylate (HDMA) has similar reactive groups to bis-GMA. This matrix has low viscosity, fast curing monomer with low volatility, hydrophobic backbone, and it is a good solvency for use in free radical polymerization (Powers and Sakaguchi, 2003). The structure of HDMA is as figured below (Valittu and Sevelius, 2000).

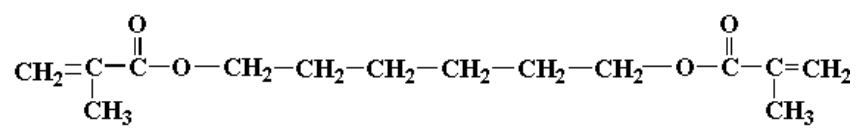

Figure 2. The structure of 1,6-Hexanediol dimethacrylate (HDMA) 
The HDMA features water repellency property (hydrophobic). It is used as a functional monomer for polymers and as a crosslinking agent between the molecular chains of polymers. The applications of HDMA include adhesives and sealants, coatings, elastomer, photopolymers electronics, improved adhesion, hardness, abrasion and heat resistance (Esstech, 2011). It is reported that HDMA does not produce mutagenic, embryotoxic, teratogenic, or reproductive effects in humans. Related to the carcinogenicity, it is reported that none of HDMA components are listed by IARC, NTP, OSHA, or ACGIH as carcinogens (Powers and Sakaguchi, 2003). Result proved that E-glass FRC with $78.4 \%$ HDMA showed good flexural strength and hardness (Siswomihardjo et al.,2012).

Dental composites are extensively used in dentistry due to their esthetic and good in physical and mechanical properties (Tuan Rahim et al., 2012). The oral environment is very moist due to the presence of water in saliva and other fluids of the mouth, and this will cause the hydration of composite. This condition will result in the swelling of the material due to the sorption of water into the resin matrix, and in turn it will plasticizes the composite (Eliades et al., 2005). It also increases the materials solubility, causes leakage of fillers which in turn breaks the bond between filler and matrix. A long term aging, for about 2 years of composites in water proved to significantly reduce the material fracture toughness (Drummond, 2008). Another issue of composite resin with oral environment is the release of unreacted monomers from the material which may stimulate the growth of bacteria and promote allergic reactions (Sideridou et al., 2004). The immersion time for most composite resins, normally will saturate within 7-60 days (Tuan Rahim et al., 2012), while materials like acrylic resin may require only in a period of 17 days to become fully saturated with water (Anusavice, 2003).

The objective of this research was to measure the weight difference, before and after immersion. This study aimed to investigate the water sorption of a new resin matrix system of FRC based on HDMA.

\section{Materials and Methods}

\subsection{Materials}

Table 1. Materials used in the study

\begin{tabular}{ll}
\hline Material & Manufacturer \\
\hline Bis-GMA & Sigma Aldrich, USA \\
Methylmethacrylate (MMA) & ProSciTech, Australia \\
1,6-Hexanediol dimethacrylate (HDMA) & Esstech, USA \\
Camphorquinone (CQ) & Esstech, USA \\
N,N-cyanoethyl methylaniline (CEMA) & Esstech, USA \\
Unidirectional E-glass fibers & Stick Tech Ltd, Turku, Finland \\
\hline
\end{tabular}

The E glass fibers (R338-2400/V/P) were already silanized by the manufacturer and kept in a desiccators for 24 hours prior to specimen preparation. The fibers were 
sized by immersion in a sizing solution for 1 minute. The sized fibers were cut into 25 $\mathrm{mm}$ long with a surgical steel knife (Matinlinna et al., 2009).

\subsection{Specimen preparation}

Two bundles of $25 \mathrm{~mm}$ long fibers reinforcement were placed along the long axis of the specimen into the mould and embedded into the resin matrix with different compositions as shown in table 2. Each group of matrix composition consisted of 5 specimens. Totally fifteen specimens with the dimension of $(2 \times 2 \times 25) \mathrm{mm}$ were prepared (Mallick, 2007). All specimens were light-cured on both sides with a light curing unit (Woodpecker, USA) for $3 \times 40 \mathrm{sec}$. After light-curing, all specimens were polished using polishing paper of 360 grit (Matinlinna et al., 2009). The specimens were immersed in distilled water for 24 hours, $37^{\circ} \mathrm{C}$ before the testing.

Table 2: Matrix composition (in wt \%) of the three groups

\begin{tabular}{cccccc}
\hline Group & \multicolumn{3}{c}{ Component (\%) } \\
\cline { 2 - 6 } & MMA & bis-GMA & HDMA & CQ & CEMA \\
\hline Group 1 & 19.6 & - & 78.4 & 1.0 & 1.0 \\
Group 2 & 49.0 & - & 49.0 & 1.0 & 1.0 \\
Group 3 & 19.6 & 78.4 & - & 1.0 & 1.0 \\
\hline
\end{tabular}

\subsection{Specimens immersion in distilled water}

All specimens were immersed in $15 \mathrm{ml}$ distilled water of $37^{\circ} \mathrm{C}$ for 21 days. The weight difference of all specimens, before and after immersion were recorded. Data obtained were analyzed by SPSS release 17.0 software. The level of statistical significant $p$ was set as 0.05 . The data normality was examined by KolmogorovSmirnov test. One way analysis of variance (ANOVA) followed by Post hoc least significant different (LSD) test were carried out. The dependent variables (weight difference) were compared with independent factor (resin matrix composition).

\section{Result}

.Table 3. Average of weight difference (\%)

\begin{tabular}{|c|l|}
\hline Group & Mean / SD \\
\hline 1 & $0.004 \pm 7.07$ \\
\hline 2 & $0.010 \pm 0.001$ \\
\hline 3 & $0.003 \pm 0.001$ \\
\hline
\end{tabular}

The weights of all specimens before and after 21 days immersion were measured, and the weight difference were calculated. Group-1 showed the lowest average $(0.004 \%)$, followed by group $3(0.003 \%)$ and group- 2 showed the highest average $(0.010 \%)$.

Table 4. The ANOVA of weight difference

\begin{tabular}{|l|r|r|r|r|r|}
\hline \multicolumn{1}{|c|}{ Weight } & Sum of Squares & Df & Mean Square & F & Sig. \\
\hline Between Groups & .000 & 2 & .000 & 32.667 & .000 \\
Within Groups & .000 & 12 & .000 & & \\
Total & .000 & 14 & & & \\
\hline
\end{tabular}


Result of the ANOVA analysis showed a significant difference $(p<0.05)$ in the average of weight difference among the three groups

Table 5. The LSD test of weight difference

\begin{tabular}{|c|c|c|c|c|c|c|}
\hline \multirow[b]{2}{*}{ (I) Material } & \multirow[b]{2}{*}{ (J) Material } & \multirow{2}{*}{$\begin{array}{l}\text { Mean Difference } \\
(\mathrm{I}-\mathrm{J})\end{array}$} & \multirow[b]{2}{*}{ Std. Error } & \multirow[b]{2}{*}{ Sig. } & \multicolumn{2}{|c|}{ 95\% Confidence Interval } \\
\hline & & & & & Lower Bound & Upper Bound \\
\hline \multirow[b]{2}{*}{ HDMA78 } & HDMA49 & $-.006000^{\star}$ & 8.717798E-4 & $.000^{*}$ & -.00790 & -.00410 \\
\hline & bis-GMA & 2.000000E-4 & 8.717798E-4 & .822 & -.00170 & .00210 \\
\hline \multirow[t]{2}{*}{ HDMA49 } & HDMA78 & $.006000^{\pi}$ & 8.717798E-4 & $.000^{*}$ & .00410 & .00790 \\
\hline & bis-GMA & $.006200^{*}$ & 8.717798E-4 & $.000^{*}$ & .00430 & .00810 \\
\hline \multirow[t]{2}{*}{ bis-GMA } & HDMA78 & $-2.000000 \mathrm{E}-4$ & 8.717798E-4 & .822 & -.00210 & .00170 \\
\hline & HDMA49 & $-.006200^{\star}$ & 8.717798E-4 & $.000^{*}$ & -.00810 & -.00430 \\
\hline
\end{tabular}

*The mean difference is significant at the 0.05 level

Further analysis with LSD proved there was a significant difference between group 1 and group $2(p<0.05)$, but no significant difference between group 1 and group $3(p>$ 0.05).

\section{Discussion}

Based on the fact that bis-GMA is considered to be relatively more cytotoxic and allergenic (Zhang and Matinlinna, 2011), the objective of this research was to replace bis-GMA to HDMA as matrix in FRC material. It is also mentioned that HDMA showed only moderate toxicity to mouse fibroblast (Thonemann et al., 2002), and a previous research proved that HDMA with the concentration of $78.4 \%$ produced good mechanical properties (Siswomihardjo et al., 2012).

Table 3 showed the average in weight difference of the three groups, before and after immersion in distilled water. This result proved there was a process of water absorbtion. It is also stated by Zhang and Matinlinna (2010), E-glass FRC continuosly absorbed water from the moment it was immersed. After polymerization composite resins are not stable and will constantly be interacting with the oral environment (Khalil, 2005). The problem associated with restorative materials is its water absorption since they continuously bathed in saliva, since water absorption may induce weakening of the matrix (Biradar et al., 2012). Water absorption for many dental materials is inevitable, since restorative materials are continually bathed in saliva (Filis and Filis, 2005). Water diffuses into the matrix causing two opposing phenomena to take place. Firstly, water will leach out free unreacted monomers and ions which will contribute to a shrinkage and loss in weight of the material. Secondly, hygroscopic absorption of water will result into a swelling and increase in weight of the material. At last, water sorption may effect composite resin by reducing the mechanical properties and wear resistance (Khalil, 2005).

Statistical analysis was performed with the ANOVA, and result showed (table 4) that matrix significantly influenced the weight difference of E-glass FRC, before and after the immersion. This result related to the statement that hydrophilicity of the polymer matrix is a factor that will influence the process of water sorption in composite resin (Tuan Rahim et al., 2012). Water sorption of composite resin is highly dependent upon 
the chemical structure of the resin monomers (Ferracane, 2006). If the monomers are hydrophilic in nature due to presence of polar groups in their structure which tends to be attracted by water molecules to form hydrogen bonding (Tuan Rahim et al., 2012). Hydrophilic resins absorb more water and expand to a greater degree than the hydrophobic resins. The volume of water is absorbed by a material is determined by the content of the hydrophilic monomers (Khalil, 2005).

The post-hoc analysis was performed using Least Significance Difference. This result might be explained due to the fact that there was a difference increase in the weight of the specimen after immersed in distilled water after the period of 21 days. There was a significant difference between group-1 and group-2 in weight difference. This result is related to the stament that FRC with $78.4 \%$ of HDMA showed good mechanical properties (Siswomihardjo et al., 2012). As for group-2 and group-3, there was also a significant difference. This is related to the fact that group-3 contains hydrophilic resin (b-GMA) which absorbs more water than HDMA as hydrophobic resins (Khalil, 2005, Ling et al., 2009). The nature of hydrophilic resin has the ability to enhance water sorption (Yiu et al., 2004), while HDMA is more hydrophobic than bisGMA (Ling et al., 2009). On the other side, between group-1 and group-3 proved no significant difference, while there should be a difference. basically b-GMA as hidrophylic resin will absorbs more water than HDMA as an hydrophobic resin. Result from this research, showed group-3 with a higher average than group-1, although statistically this difference is not significant. Based on this result, it can be explained although bis-GMA has different property from HDMA, but with the same concentration of bis-GMA and HDMA it will result in a comparable water sorption.

\section{Conclusion}

The effect of different resin matrixes and concentrations on water sorption has been studied. It showed that HDMA as hydrophobic resin matrix has higher average of weight difference than bis-GMA. This is due to HDMA which absorps less water than bis-GMA. Finally, it can be concluded that fiber reinforced composite based on $78.4 \%$ HDMA matrix system (group-1) is comparable to $78.4 \%$ bis-GMA matrix system (group-3) on its water absorption.

\section{References}

Anusavice KJ. Phillip's Science of Dental Materials, $11^{\text {th }}$ ed, Elsevier Science, St Louis, 2009, p.77.

Biradar B., Biradar S., Arvind MS. Evaluation of the Effect of Water on Three Different Light Cured Composite Restorative Materials Stored in Water: An in Vitro Study. Int J of Dent., vol 2012, Article ID 640942.

Drummond JL. Degradation Fatigue and Failure of Resin Dental Composite Materials. J Dent Res 2008, 87: 3.

Eliades G., Watts DC., and Eliades T. Dental Hard Tissues and Bonding: Interfacial Phenomenon and Related Properties. Springer, Berlin. 2005, p 80-83. 
Esstech. Material Safety Data Sheet. Product: 1,6-Hexanediol Dimethacrylate, code: X 887 7446, Esstech, USA, 2011, p 1-8.

Ferracane JL. Hygroscopic and Hydrolytic Effects in Dental Polymer Networks. Dent Mater 2006, 22 (3): 211-222.

Filis K., Filis Y. The Weight Change of Various Lightcured Restorative Materials Stored in Water. J Contemp Dent Pract 2005, 2 (6): 77-79.

Freilich MA., Meiers JC., Duncan JP., Goldberg AJ. Fiber-Reinforced Composites in Clinical Dentistry. Quintessence Publishing Co. Inc., Illinois. 2000,p 1-3.

Garoushi S., Lassila L., Vallittu PK. Resin-Based Fiber-Reinforced Composite for Direct Replacement of missing Anterior Teeth: A Clinical Report. Int J of Dentistry. Vol 2011. Article ID 8455420.

Hobkirk JA, Watson RM, Searson LJJ. Introducing Dental Implants. Churchill Livingstone, London, 2003, p. 22-25.

Khalil WM., Measurement of Water Sorption of Five Different Composite Resin Materials. J Bagh College Dent. 2005, 17 (3): 37-41.

Le Bell-Ronnlof AM. Fiber-reinforced Composites available at http://www.doria.fi/ bitstream/handle/10024/33576/D780.pdf?sequence=1,pg 22-24 on January 22, 2012.

Ling L., Xu X., Choi GY., Billodeaux D., Guo G., Diwan RM. Novel F-Releasing Composite with Improved Mechanical Properties. J Dent Res. 2009. 88 (1): 83-88.

Mallick PK., Fiber-Reinforced Composites: Materials, Manufacturing and Design, 3rd., CRC Press. Boca Roca, 2007. p 42-47.

Matinlinna JP., Dahl JE., Karlsson S., Lassila LV., Valittu PK. In Silanes and Other Coupling Agents. Vol 5. VSP/Brill, Leiden, The Netherlands, 2009. p. 107-121.

McCabe JF, Walls AWG. Applied Dental Materials. $9^{\text {th }}$ ed. Blackwell Munsgaard, Oxford, pp.213-215.6. Mallick PK. Fiber-reinforced composites : materials, manufacturing and design, $3^{\text {rd }}$ ed. CRC Press, Boca Raton, 2007, p. 42-58.

Moharamzadeh K., Brook IM., Van Noort R. Biocompatibility of Resin-based Dental Materials. Materials 2009, 2, 514-548; doi:10.3390/ma2020514.

Powers JM., Sakaguchi RL. Restorative Dental Materials. 12th ed. Evolve, Missouri, 2003, p 229.

Schutt A., Burki G., Schwaller P., Michler J., Cattani-Lorente M., Vallitu P., Bouillaguet $S$. Mechanical Properties of Fibre-reinforced dental Composites Subjected to Hydrothermal and Mechanical Ageing. Euro Cells and Mater. Vol. 7 - Suppl 2. 2004. 
Sideridou I., Achilias DS., Spyroudi C., Karabela M. Water Sorption Characteristics of Light-Cured Dental Resins and Composites Based on Bis-EMA/PCDMA. Biomaterials. 2004. (25): 367-376.

Siswomihardjo W., Sunarintyas S., Martosudjijo W., Irnawati D., Zhang M., Matinlinna JP. Biomechanical Properties of a New Fiber-Reinforced Composites. Presented at IADR Helsinki, Finlandia. 2012.

Soderholm KJ, Marioti A. Bis-GMA Based Resins in Dentistry: Are They Safe ?. JADA 1999; 130: 201-209.

Stoeva I.,Kisselova A., Zekova M. Allergic Contact Stomatitis from bisphenol-AGlycidil methacrylate During Application of Composite Restorations. A case report. J of IMAB., Annual proceeding, book 2, 2008, p 45-46.

Tuan Rahmi TNA., Mohamad D., Akil HM., Abdul Rahman I. Water Sorption Characteristics of Restorative Dental Composites Immersed in Acidic Drinks. Dent Materials. 2012. (28): 63-70

Vallittu PK. The Effect of Glass Fiber Reinforcement on the Fracture Resistance of Provisional Fixed Partial Denture.J Prosthet Dent 1998;79:125 - 130.

Vallittu PK. Flexural Properties of Acrylic Resin Polymers Reinforced with Unidirectional and Woven Glass Fibers.J Prosthet Dent 1999;81:318 - 326.

Vallittu PK. Strength and Interfacial Adhesion of FRC-tooth System. In: Vallittu PK, editor. The Second International Symposium on Fibre-Reinforced Plastics in Dentistry. University of Turku, Institute of Dentistry and Biomaterials Research; 2002.

Valittu PK., Sevelius C. Resin-bonded, Glass Fiber-Reinforced Composite Fixed Partial Dentures: A Clinical Study. J Prosthet Dent. 2000. (84): 413-418.

Van Noort R. Introduction to Dental Materials. 3rd Ed. Elsevier Health Sciences. London.p 120. 2007

Yiu CKY., King NM., Pashley DH., Suh BI., Carvalho RM., Carrilho MRO., Tay FR. Effect of Resin Hydrophilicity and Water Storage on Resin Strength. Biomaterials. 2004. (25): 5789-5796.

Thonemann B., Schmalz G., Hiller KA. Schweiki H. Responses of L929 mouse fibroblast, primary and immortalized bovine dental papilla-derived cell lines to dental resin components. J Dent Materials 18 (2002):318-323.

Zhang M., and Matinlinna JP. The Effect of Resin Matrix Composition on Mechanical properties of E-glass Fibre-Reinforced Composite for Dental Use. $J$ of Adhesion Science and Tech. 2011. 19(25): 2687-2701, DOI: 10.1163/016942411x556051

Zhang M., Matinlinna JK. E-Glass Fiber Reinforced Composites in Dental Applications. Silicon 2012: (4): 73-78. 


\section{Aknowledgement}

Esstech Inc. (Essington, PA, USA) is acknowledged for generously donating some materials for this study. Stick Tech Ltd. (Turku, Finland) via Dr. J.P. Matinlinna is gratefully thanked for the E-glass fiber materials. 